\title{
Submucosal pocket-assisted enucleation of gastric submucosal lesions
}

\section{Georgios Mavrogenis, Dimitrios Ntourakis, loannis Tsevgas, Dimitrios Zachariadis}

Mediterraneo Hospital, Athens, Greece

Identifying and resecting gastric submucosal lesions through submucosal tunneling is not always easy, because of difficulties in orientation or a lack of sufficient working space. This article presents the resection of two gastric lipomas with a modified pocket-creation method (Fig. 1), initially scheduled for endoscopic submucosal dissection (ESD) of epithelial lesions [1].

A 63-year-old male was referred for endoscopic resection of two submucosal lesions of the antrum for both diagnostic and therapeutic purposes (Fig. 2). The procedure was undertaken under general anesthesia. Both lesions were resected as follows. A mixture of indigo carmine and hydroxyethyl starch was injected and a $2-\mathrm{cm}$ horizontal mucosal incision was made at the proximal border of the lesion with a tip-cutting knife (Splash-M Knife, Pentax, Japan). Then, a submucosal pocket, $2-3 \mathrm{~cm}$ in depth, was created using Endocut Q, Effect 3 (VIO3, ERBE, Germany). The tumors were progressively enucleated through the submucosal pocket by means of standard ESD techniques. At the end of the procedure, both submucosal entrances were closed with hemostatic clips. The patient received doubledose proton pump inhibitor treatment; he was discharged $24 \mathrm{~h}$ later and had an uneventful recovery. Both lesions had histology features of benign lipomas.

In conclusion, this image illustrates a modified ESDderived technique for the resection of gastric submucosal tumors. Enucleation of the lesion is achieved through a submucosal pocket that offers more space and better orientation compared to the standard tunneling technique,

Mediterraneo Hospital, Athens, Greece

Conflict of Interest: None

Correspondence to: Georgios Mavrogenis, Kavetsou 10, 81132 Mytilene, Greece, Tel.: +30 22510 55557, email: mavrogenis@gmail.com

Received 26 February 2017; accepted 05 March 2017; published online 23 March 2017

DOI: https://doi.org/10.20524/aog.2017.0137

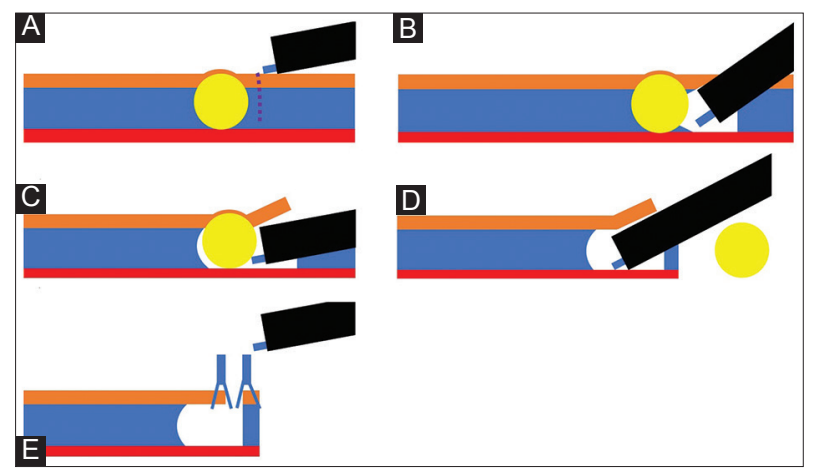

Figure 1 (A) A small incision was made just proximally to the lesion. (B, C) A submucosal pocket was created, (D) and the lesion was enucleated. (E) Optional closure of the pocket with clips

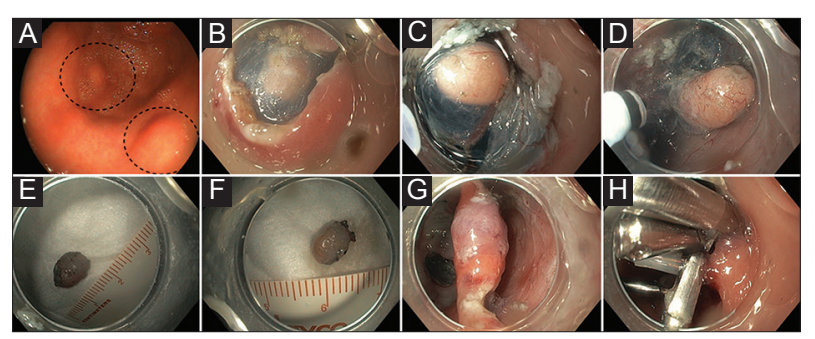

Figure 2 (A) Two synchronous gastric submucosal lesions. (B) Creation of a submucosal opening. (C, D) Progressive enucleation. (E, F) Enbloc resection of both lesions. $(\mathrm{G})$ Endoscopic view of the two pockets prior to endoscopic closure. $(\mathrm{H})$ Complete closure of the entrances with endoscopic clips

while preserving the choice of closing the artificial ulcer with the mucosal flap.

\section{Reference}

1. Miura Y, Hayashi Y, Lefor AK, Osawa H, Yamamoto H. The pocketcreation method of ESD for gastric neoplasms. Gastrointest Endosc 2016;83:457-458. 